\title{
Computed tomography of the spleen: how to interpret the hypodense lesion
}

\author{
Christoph A. Karlo • Paul Stolzmann • \\ Richard K. Do • Hatem Alkadhi
}

Received: 20 August 2012 /Revised: 30 October 2012 / Accepted: 31 October 2012 / Published online: 4 December 2012

(C) The Author(s) 2012. This article is published with open access at Springerlink.com

\begin{abstract}
Background As the largest single lymphatic organ in the human body, the spleen is responsible for central immunological and haematological tasks. Therefore, the spleen can be subject to a wide range of pathologic disorders. Computed tomography (CT) represents the most widely applied cross-sectional abdominal imaging technique and is considered the imaging modality of choice for the evaluation of numerous abdominal pathological conditions. Hypodense splenic lesions are frequently encountered on abdominal CT images. Although most hypodense lesions of the spleen can be considered benign, some findings and clinical conditions warrant closer attention to the lesion. CT offers a number of morphological criteria that can be applied to differentiate hypodense lesions of the spleen, such as a the appearance of a lesion's borders, its attenuation, as well as the presence of calcifications or solid components.

Methods This article reviews the most common splenic pathologies leading to hypodense appearances on CT images and illustrates the key CT imaging findings in the context of the clinical history of the patients.

Conclusion The key imaging findings of hypodense splenic lesions are presented in order to aid interpretation during routine evaluation of abdominal CT images.

Teaching Points

- Haemangiomas, congenital in origin, represent the most common benign lesions of the spleen.
\end{abstract}

C. A. Karlo • R. K. Do

Department of Radiology, Memorial Sloan-Kettering Cancer

Center, New York NY, USA

P. Stolzmann $\cdot$ H. Alkadhi $(\square)$

Institute of Diagnostic and Interventional Radiology,

University Hospital Zurich, Raemistrasse 100,

8091 Zurich, Switzerland

e-mail: hatem.alkadhi@usz.ch
- Lymphoma represents the most common malignant tumour of the, usually secondarily involved, spleen.

- Most hypodense splenic lesions on CT represent benign lesions that require no further work-up.

- For correct interpretation, hypodense splenic lesions need to be evaluated in the clinical context.

Keywords Computed tomography $\cdot$ Spleen $\cdot$ Hypodense lesion - Abdominal pathology

\section{Introduction}

Focal hypodense lesions of the spleen are frequently encountered on computed tomography (CT) images of the abdomen. Although the majority of hypodense splenic lesions do not require dedicated management or follow-up, some findings warrant closer attention [1]. Interpretation of a hypodense lesion in the spleen can be challenging, and often can only be performed correctly when certain imaging patterns are considered and the clinical history is taken into account. The purpose of this article is to review and discuss the characteristic CT imaging findings of hypodense lesions of the spleen and to illustrate selected cases in the context of the patient's history.

\section{The normal spleen}

Size and shape of the spleen exhibit a wide variability. While the shape is influenced by adjacent organs, determination of the normal size of the spleen can be tricky. It has been suggested, that - on transverse CT images - a maximum diameter of up to $10 \mathrm{~cm}$ and a perpendicular diameter of up to $6 \mathrm{~cm}$ can be considered normal. In adults, the craniocaudal diameter usually does not exceed $15 \mathrm{~cm}[2,3]$. 
On non-contrast-enhanced CT images, the healthy spleen usually has a density of around 45 Hounsfield Units (HU) (Fig. 1a). A diffuse increase in splenic density can be observed in patients with haemosiderosis, sickle-cell disease and lymphoma. On contrast-enhanced, arterial-phase CT images, the spleen typically shows a heterogeneous (i.e. trabecular or serpentine) enhancement pattern due to variable flow rates of contrast-enhanced blood through the sinuses of the red pulp (Fig. 1b). Awareness of this irregular enhancement pattern is essential, because underlying pathologies or focal traumatic lesions may be obscured. On contrast-enhanced, portal venous-phase CT images, healthy splenic parenchyma has a homogenous appearance (Fig. 1c). Thus, contrast-enhanced, portal-venous phase CT images should be evaluated when searching for and interpreting lesions of the spleen.

\section{Cysts}

Splenic cysts can be divided into true (i.e. primary) and false (i.e. secondary) cysts. True splenic cysts can be further divided into parasitic and non-parasitic (i.e. congenital and neoplastic) cysts [4]. While true cysts have epithelial lined walls, the borders of false cysts are composed of dense, fibrous tissue without an epithelial lining. It is impossible to differentiate between true and false splenic cysts by the CT imaging appearance itself. However, in clinical routine this differentiation is usually not relevant, because cysts without inherent solid components, wall-thickening or contrast-enhancement can be safely considered benign. However, it is important to note that cysts may cause complications, including infection, rupture and haemorrhage, and thus may cause clinical symptoms such as fever, upper left quadrant pain or jaundice.

\section{Parasitic cysts}

Parasitic cysts are caused by splenic involvement in hydatid disease, primarily due to infection with Echinococcus granulosus (Fig. 2a). While primary hydatid disease of the spleen is rare, secondary splenic involvement can either be caused by systemic (i.e. haematogenous) infection or subsequent to rupturing of a hepatic hydatid cyst and abdominal spread of parasites [5, 6]. Clinical manifestations of echinococcosis are rather unspecific and may include abdominal pain and fever. In case of known hepatic or pulmonary hydatid disease, a newly diagnosed cystic lesion of the spleen needs to be regarded as splenic disease involvement, especially in patients from endemic regions such as westcentral Europe, Turkey, most areas of the former Soviet Union, Iran, Iraq, western and central China as well as northern Japan and the northern parts of the United States.

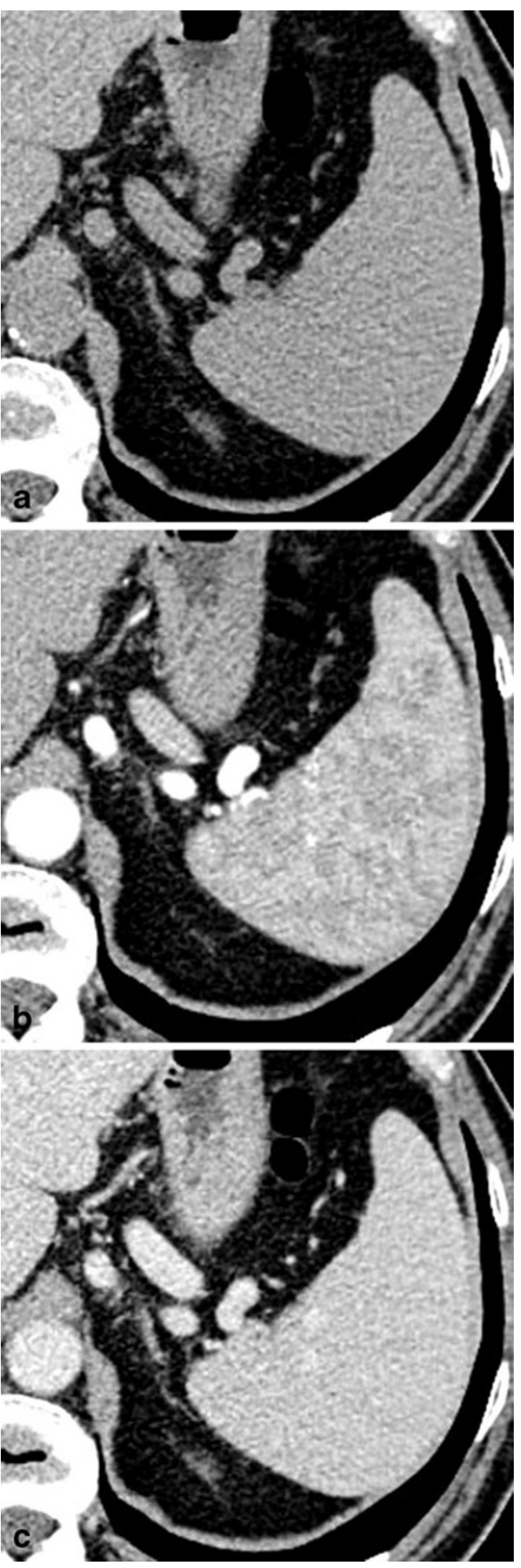

Fig. 1 Transverse CT images acquired (a) before and (b, c) after the intravenous administration of iodinated contrast material in a 38 -yearold man. b Note the trabecular enhancement pattern of the spleen during the arterial phase, when compared with the homogeneous appearance of the spleen during the (c) portal venous phase and on the (a) non-enhanced image

On contrast-enhanced CT, parasitic cysts may present as unilocular or multilocular and can be found anywhere 
Fig. 2 Transverse contrastenhanced CT images acquired during the portal-venous phase illustrating the different appearances of cystic splenic lesions. a A 73-year-old man with hydatid disease of the spleen (arrow). b A 23-year-old man with a congenital cyst of the spleen exhibiting water-like attenuation values. c A 52-year-old man with a multicystic metastasis from colon cancer (arrow). d A 63year-old man with a false cyst, presumably after trauma (arrow)
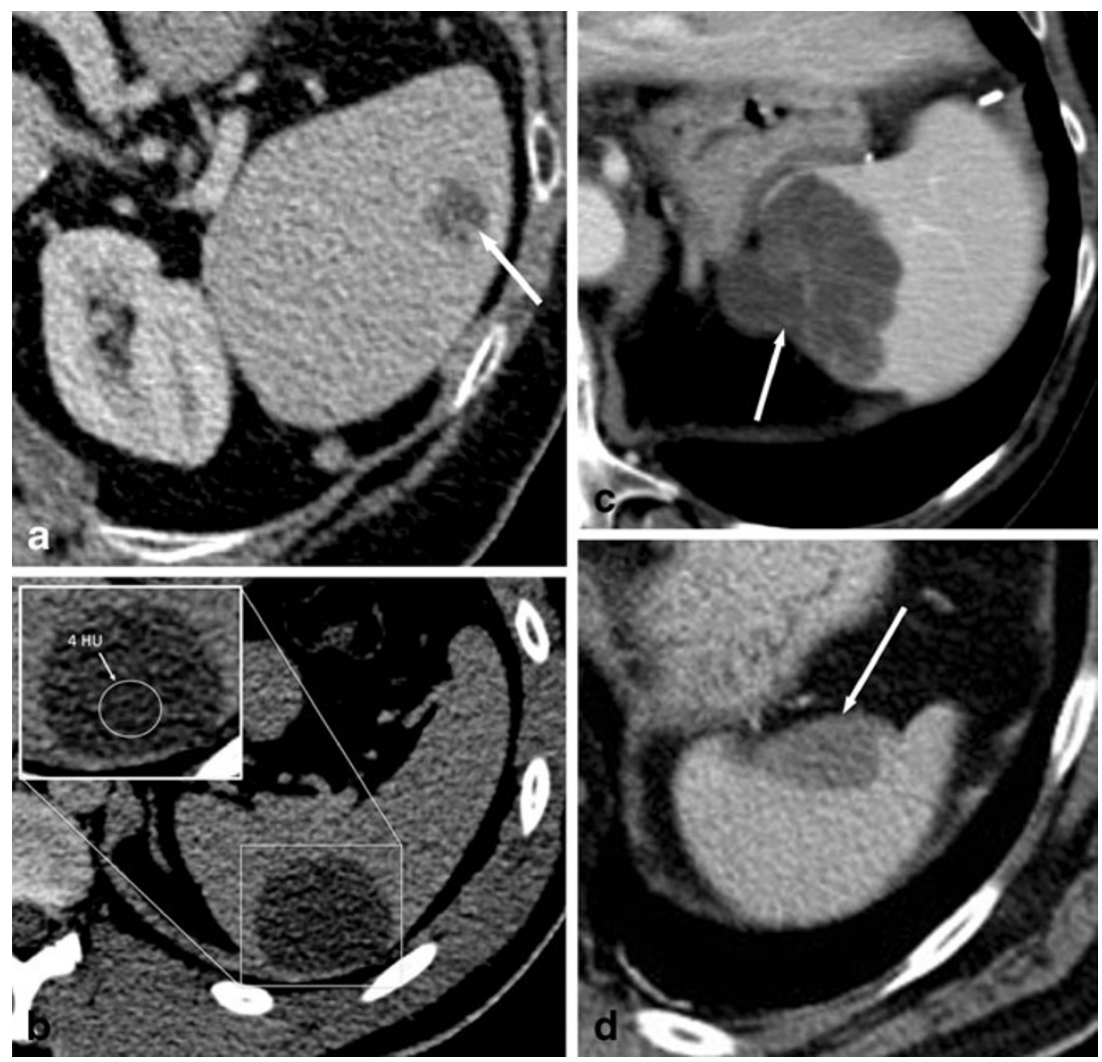

within the spleen. Parasitic cysts are well-defined, demonstrate homogeneous fluid content with attenuation values similar to water and do not exhibit contrast-enhancement. In addition, a Waterlilly sign is frequently observed [7]. Wall calcifications may occur as parasites die. As parasitic cysts grow larger, a mass effect can lead to splenomegaly $[5,6]$.

\section{Congenital cysts}

Congenital cysts account for $2.5 \%$ of splenic cysts and are usually detected incidentally in children and young adults $[8,9]$. Although they are mostly stable in size and remain asymptomatic, large cysts may cause symptoms due to a mass-effect.

On contrast-enhanced CT, congenital cysts can be unilocular or multilocular and can be found anywhere within the spleen. They appear as well-defined, thin-walled, spherical lesions with homogeneous content and water-like attenuation values around $0-10 \mathrm{HU}$ [10] (Fig. 2b). Wall trabeculations or peripheral septations can be seen in up to $86 \%$ of cases on CT and wall calcifications in up to $14 \%$ [11]. Congenital cysts do not exhibit contrast enhancement.

\section{Neoplastic cysts}

Neoplastic cysts may be associated with splenic metastases (Fig. 2c), lymphangiomas and haemangiomas. They usually represent true cysts. Wall thickening and adjacent solid, contrast-enhancing components facilitate the differentiation between benign and malignant cystic lesions.

\section{False cysts}

False cysts account for approximately $80 \%$ of splenic cysts and are also referred to as secondary cysts. They mostly originate as a consequence of trauma, infection or infarction and are thought to represent the end-stage of intraparenchymal haematomas.

On contrast-enhanced CT, false cysts can be unilocular or multilocular in appearance, are well-defined and usually located close to the capsule of the spleen. Wall calcifications are observed more commonly than in true cysts (up to $50 \%$ of cases; Fig. 2d) [11].

\section{Splenic trauma}

The spleen is a highly vascularised organ, receives up to $5 \%$ of the cardiac output, and contains approximately $500 \mathrm{ml}$ of blood in reserve. In blunt abdominal trauma situations, the spleen is the most commonly affected organ [4]. Due to its anatomical structure, thin capsule, ligamentous fixation and intraperitoneal location, the spleen has a large potential for uncontained haemorrhage. The risk of splenic injuries increases in case of splenomegaly. The spectrum of injuries includes subcapsular, intraparenchymal or perisplenic 
haematomas as well as lacerations, ruptures and infarctions due to vascular injuries, as well as contained vascular injuries such as pseudoaneurysm and arteriovenous fistula [12]. In severe trauma, the spleen can rupture and multiple, devascularised splenic fragments can be seen in the left upper quadrant of the abdomen. Usually, splenic ruptures are associated with extensive intraperitoneal haemorrhage. Traditionally, splenic injuries are classified according to the splenic injury grading system of the American Association for the Surgery of Trauma [13]. In addition, multiple CT grading systems had been proposed by various authors [14], as contrast-enhanced $\mathrm{CT}$ is an excellent imaging modality for the assessment of traumatic lesions of the spleen [15]. However, care needs to be taken not to misinterpret congenital anomalies of the spleen such as lobulations or splenic clefts for splenic injuries.

On non-contrast-enhanced CT images, haematomas can present as either intraparenchymal, subcapsular or perisplenic fluid collections with increased density $(>30 \mathrm{HU}$; Fig. 3a) [12]. Extravasation of contrast material can sometimes be seen on contrast-enhanced CT images (Fig. 3b).

On contrast-enhanced CT images, splenic lacerations mostly present themselves as ill-defined, irregular, geographic hypodense areas within the spleen due to a lack of perfusion with contrast material. Lacerations can be located anywhere in the spleen (i.e. centrally, close to the hilum, subcapsular). On non-contrast-enhanced CT images, the density of lacerations is usually higher than the density of the normal spleen due to haemorrhage. Large lacerations or intraparenchymal haematomas can cause a mass effect, which is also responsible for clinical symptoms including left upper quadrant pain.

\section{Splenic abscess}

The prevalence of splenic abscesses during autopsy had been reported between $0.14 \%$ and $0.7 \%$ [16]. Over the last two decades, the incidence of splenic abscesses has increased due to the wide-spread use of immunosuppression in patients with organ transplantation, the more common use of chemotherapy and corticosteroids as well as a greater incidence of AIDS. Splenic abscesses include pyogenic, fungal and tuberculous abscesses.

Pyogenous abscesses are caused by either haematogenous spread of bacteria (i.e. Staphylococcus, Streptococcus, Escherichia coli or Salmonella), penetrating trauma, prior splenic infarction or contiguous infection (i.e. from perinephric abscess or pancreatitis) [17, 18]. Most pyogenic abscesses are unilocular, but can be multifocal in up to $26 \%$ of cases [18-21]. On contrast-enhanced CT images, pyogenic abscesses typically exhibit a "rim-enhancement" of the outside-facing portion of the abscesses' wall (Fig. 4a).

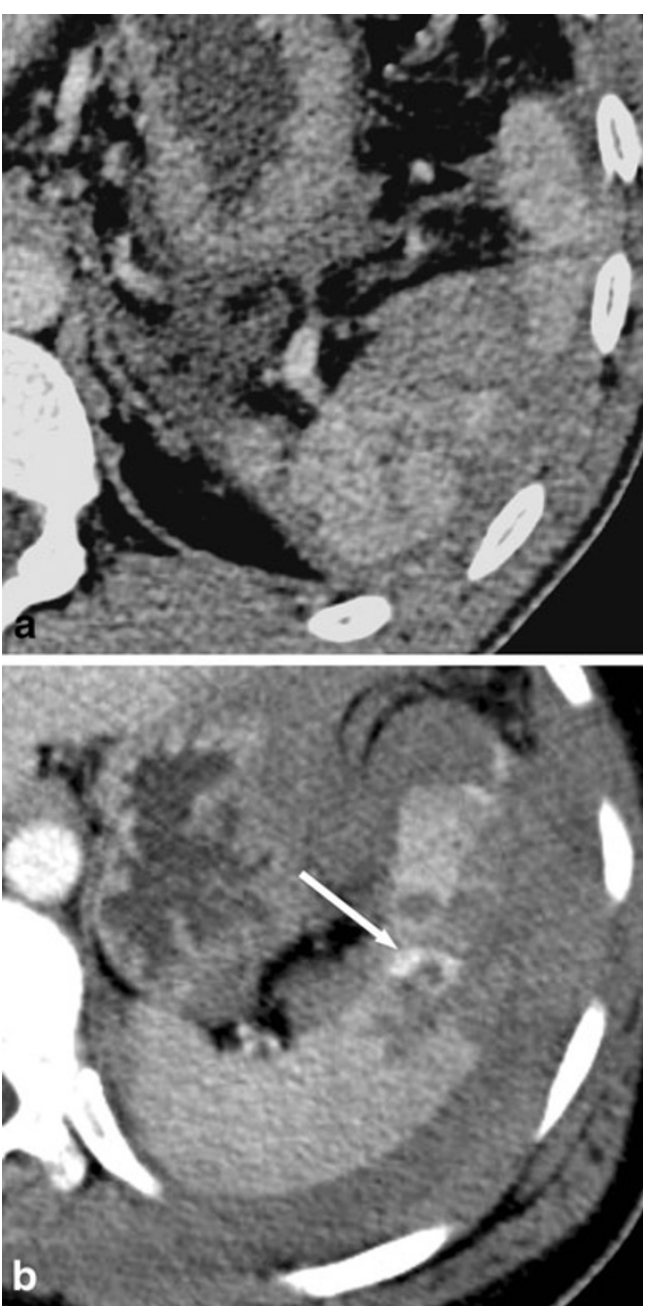

Fig. 3 Transverse contrast-enhanced CT images acquired during the late arterial phase. a A 23-year-old man who was involved in a motorcycle accident and suffered a splenic laceration with extensive intraparenchymal, subcapsular and perisplenic haematoma. b A 34year-old woman who was involved in a motor vehicle accident and suffered a splenic laceration. Note the active contrast extravasation within the spleen (arrow)

The inside-facing portions of the wall usually show lessenhancing or non-enhancing components, which represent fibrous and proteinaceous material. The content of a pyogenic abscess usually appears inhomogeneous with density values ranging from 20 to $40 \mathrm{HU}$. Gas formations within the abscess can be encountered and usually confirm the diagnosis of a pyogenic abscess (Fig. 4b).

Fungal abscesses are mostly multifocal (i.e. up to $90 \%$ ), smaller than pyogenic abscesses $(<2 \mathrm{~cm})$, and do not show rim enhancement on contrast-enhanced CT images. Due to their small size, lack of contrast enhancement and miliary pattern, fungal abscesses can be difficult to detect on CT images. Therefore, CT cannot reliably rule out fungal abscesses, as enlargement of the spleen remains the only imaging finding at times. 

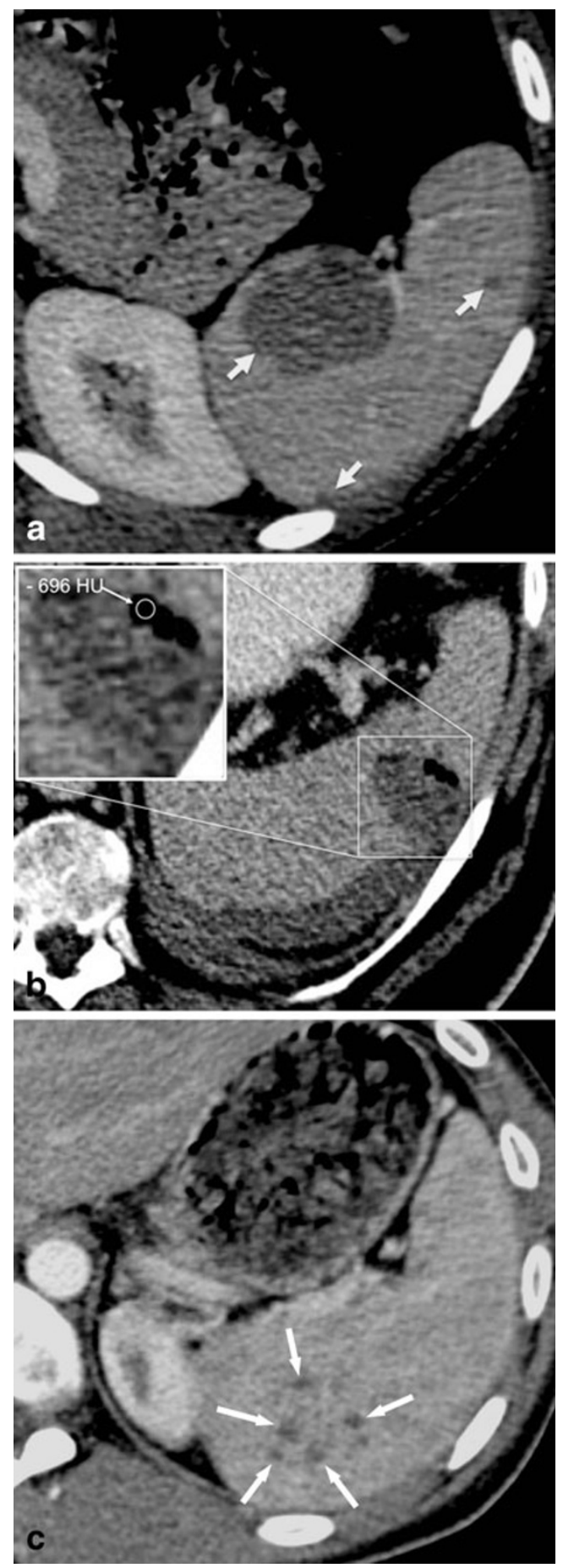

Fig. 4 Transverse contrast-enhanced CT images acquired during the portal-venous phase. a A 19-year-old woman with multiple pyogenic splenic abscesses during a period of immunosuppression and haematogenous spread of Staphylococcus aureus (short arrows). b A 48year-old man with a pyogenic splenic abscess exhibiting gas formations and subcapsular fluid accumulation due to a spontaneous rupture of the abscess. c A 27-year-old man with multiple tuberculous abscesses (long arrows)

Tuberculous abscesses of the spleen, usually confirmed during autopsy $[22,23]$, can sometimes be seen in patients with severe, disseminated tuberculous disease. However, in patients with known pulmonary tuberculosis, the presence of multiple, small, hypodense, splenic lesions on contrastenhanced CT needs to be regarded as abdominal tuberculous spread, unless proven otherwise. Tuberculous abscesses are usually small $(<2 \mathrm{~cm})$, ill-defined and can show mild contrast-enhancement (Fig. 4c) [24].

\section{Sickle cell disease}

While passing through the sinuses of the red pulp, the blood's haematocrit increases by approximately $60 \%$ due to plasma removal. In addition, the blood flow decelerates to allow for maximal interaction of antigenic material and structurally abnormal erythrocytes with macrophages and reticuloendothelial cells. In order to survive this process, erythrocytes need to be deformable in order to pass through tiny slits between endothelial cells. In patients with sickle cell disease, erythrocytes are rigid and frequently occlude the small sinuses of the red pulp. This leads to microinfarctions and micro-haemorrhage, which then become visible on contrast-enhanced CT as small, disseminated hypodense, ill-defined lesions. In the early course of the disease, the spleen can be enlarged. As the disease advances, the spleen loses more and more of its function, shrinks and may become calcified (Fig. 5). Therefore, in patients with sickle cell disease, the presence of multiple small hypodense splenic lesions is strongly suggestive of sickle cell-induced splenic infarctions.

\section{Infarction}

Splenic infarction is caused by a lack of perfusion of either certain regions of the spleen (Fig. 6a) or the entire organ (Fig. 6b). The most common event leading to infarctions of the spleen is partial or total occlusion of the splenic artery or its branches. Patients typically present with left upper quadrant abdominal pain, but without fever. Large splenic infarctions are usually caused by thromboembolic conditions mostly originating from atrial fibrillation, whereas microinfarctions can be seen in patients with sickle cell anaemia, lymphoma and leukaemia.

On contrast-enhanced CT images, splenic infarctions present as wedge shaped, hypodense areas with the base facing the splenic capsule. Enhancement of the affected region can be observed on delayed-phase images. Splenic infarctions can cause a mass effect and may present as illdefined areas during early stages and well-defined areas during late stages. The development of secondary abscesses or splenic rupture and subsequent haemorrhage represent potential complications secondary to splenic infarction. 

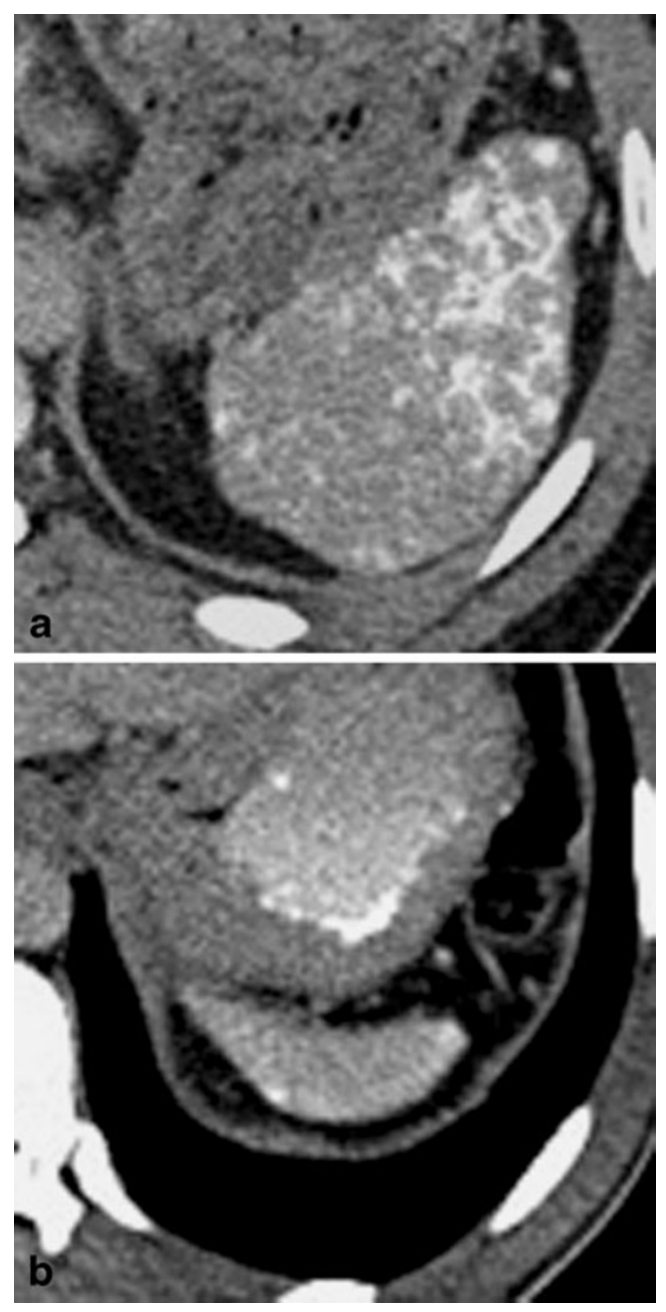

Fig. 5 Transverse contrast-enhanced CT images acquired during the portal venous phase. a A 43-year-old man with advanced sickle-cell disease. Note the irregular shape of the spleen, as well as the increased density of the splenic parenchyma, together with extensive calcifications as a consequence of constantly occurring micro-infarctions. b A 38-year-old man with sickle-cell disease exhibiting end-stage splenic involvement. Note the increased density, calcifications of the shrunken spleen

\section{Hamartoma}

Hamartomas of the spleen, also referred to as splenomas, are benign and typically asymptomatic lesions which are often discovered incidentally on imaging. They can be associated with tuberous sclerosis and Wiskott-Aldrich like syndrome. Hamartomas do not possess a capsule. The histological structure consists, depending on the type, of a mixture of either red or white pulp elements.

On contrast-enhanced CT, hamartomas appear as solitary, well-defined, solid lesions that can show prolonged contrastenhancement due to stagnant blood flow within the sinuses of the red pulp (Fig. 7a) [25-27]. Calcifications, central areas of necrosis as well as macroscopic fat may be observed. Fat can be detected on $\mathrm{CT}$ as areas with negative attenuation (Fig. 7b).
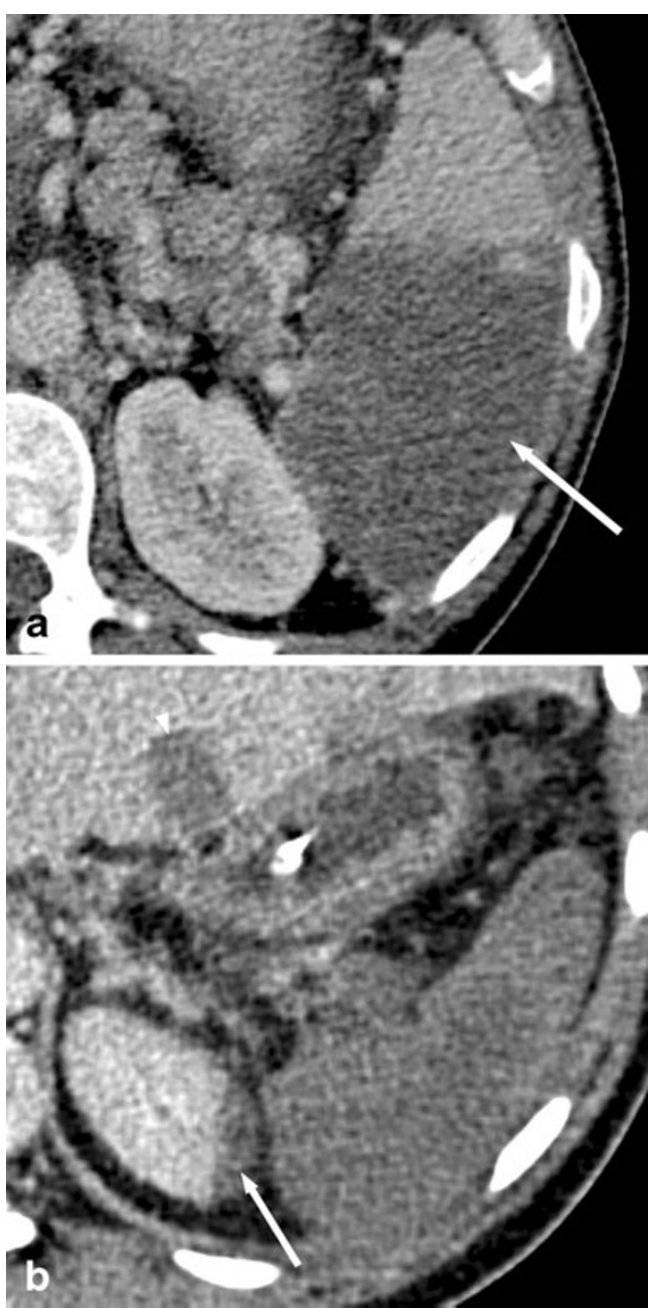

Fig. 6 Transverse contrast-enhanced CT images acquired during the portal-venous phase. a A 49-year-old woman with a large splenic infarction secondary to thromboembolism from atrial fibrillation. b A 42-year-old woman with a complete splenic infarction, partial renal infarction (arrow) and hepatic infarction (arrowhead) due to a cardiogenic shock caused by sudden cardiac arrest

The prolonged enhancement on CT assists in differentiating hamartomas from malignant tumours of the spleen $[25,28]$.

\section{Haemangioma}

Haemangiomas account for the most common primary benign splenic neoplasm, with a reported autopsy prevalence of up to $14 \%$ [29]. Multiple haemangiomas can be observed predominantly in systemic angiomatosis patients (i.e. Beckwith-Wiedemann, Klippel-Trenauney-Weber and Turner syndromes). Haemangiomas, congenital in origin, consist of vascular channels filled with slow-flowing blood.

On non-contrast-enhanced CT images, most haemangiomas are isodense or hypodense when compared with normal splenic parenchyma. After the administration of contrast 

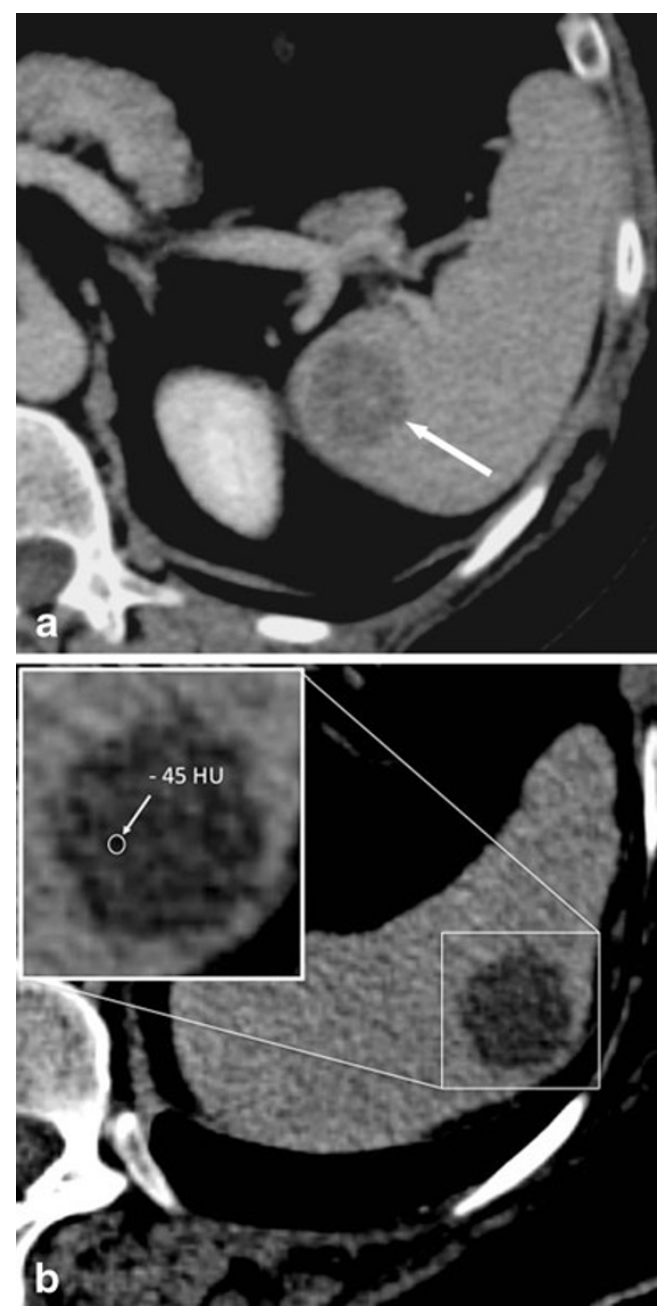

Fig. 7 Transverse contrast-enhanced CT images acquired during the portal-venous phase. a A 54-year-old woman with a hamartoma that exhibits mild contrast enhancement. b A 76-year-old woman with a hamartoma that presents with focal areas of fat attenuation

material, haemangiomas typically exhibit early, peripheral nodular enhancement, which extends towards the centre of the well-defined lesion over time [27, 30, 31] (Fig. 8). However, the enhancement pattern can differ especially in cavernous haemangiomas due to the presence of fibrosis and micro-infarctions. Due to the variable enhancement pattern and differences in timing during the administration of contrast material, haemangiomas may appear slightly larger or smaller on follow-up CT images at times. The most important-though very rare-complication of splenic haemangiomas is their spontaneous rupture, which can result in extensive intraperitoneal haemorrhage.

\section{Lymphangioma}

Lymphangiomas of the spleen are usually detected incidentally in children and young adults. They are typically located
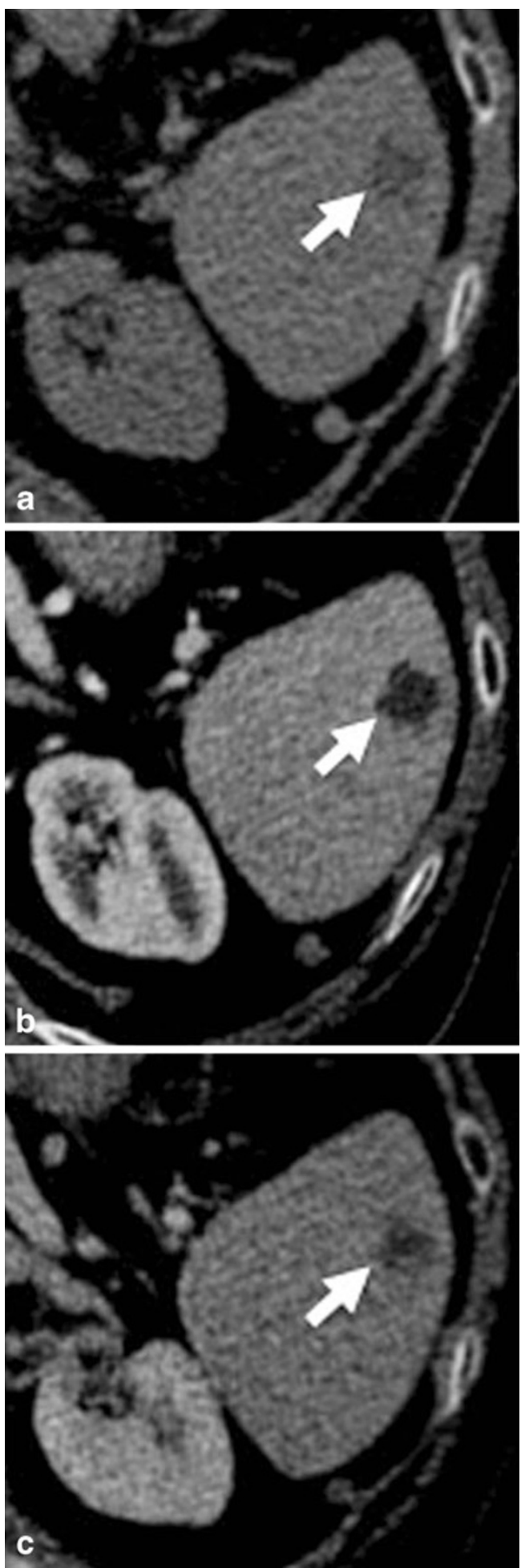

Fig. 8 Transverse CT images acquired (a) before and (b, c) after intravenous administration of iodinated contrast material in a 74year-old woman with a splenic haemangioma. Note the typical nodular enhancement beginning in the arterial phase and extending in a centripetal manner during the portal-venous phase

close to the splenic capsule and may be unilocular or multilocular in appearance. 
On contrast-enhanced CT images, lymphangiomas present as well-defined lesions. The walls of the vascular channels, which comprise splenic lymphangiomas, are thin, and contrastenhancing components are not identified on CT [32] (Fig. 9). Focal scars may be present. Lymphangiomas are congenital malformations, which can become life-threatening in children with lymphangiomatosis. However, isolated splenic lymphangioma is very uncommon in adults. Large lymphangiomas can become symptomatic due to a mass effect and splenomegaly.

\section{Sarcoidosis}

Sarcoidosis is a granulomatous systemic disease of unknown aetiology that can affect numerous organs and locations, infrequently involving the spleen.

On contrast-enhanced CT, the most important finding in patients with sarcoidosis is splenomegaly. However, small hypodense, ill-defined lesions with contrast-enhancement may also be encountered (Fig. 10). Usually the granulomas do not enhance more than healthy spleen; however, their attenuation is higher than that of splenic cysts. Lymphadenopathy in the splenic hilum is an important adjacent finding that often suggests the diagnosis of splenic sarcoidosis.

\section{Peliosis}

Peliosis of the spleen is rare, since the liver is usually the primary organ affected by this disease. Peliosis is usually

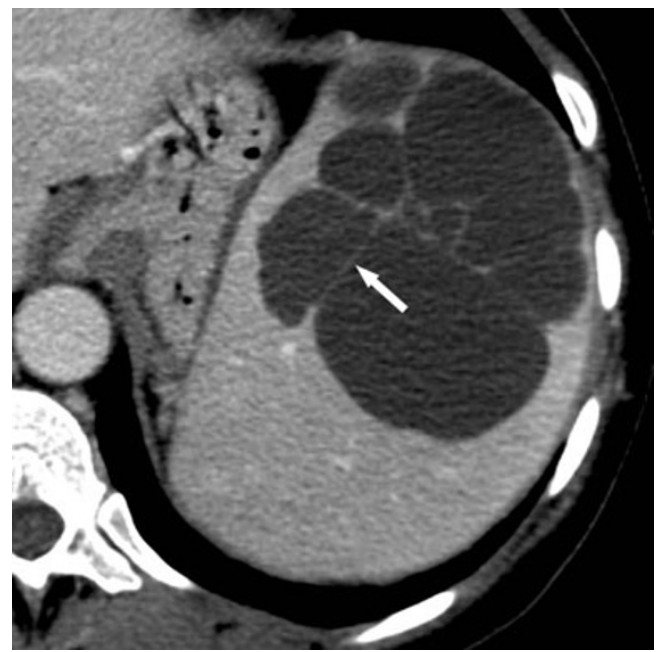

Fig. 9 Transverse contrast-enhanced CT image acquired during the portal-venous phase in a 38-year-old woman illustrating a lymphangioma of the spleen. Note the lesion's septations (arrow) that may enhance slightly after the administration of intravenous contrast material and homogeneous water-like content in the absence of solid components. The most important differential diagnosis to consider in this case would be a hydatid (echinococcal) cyst
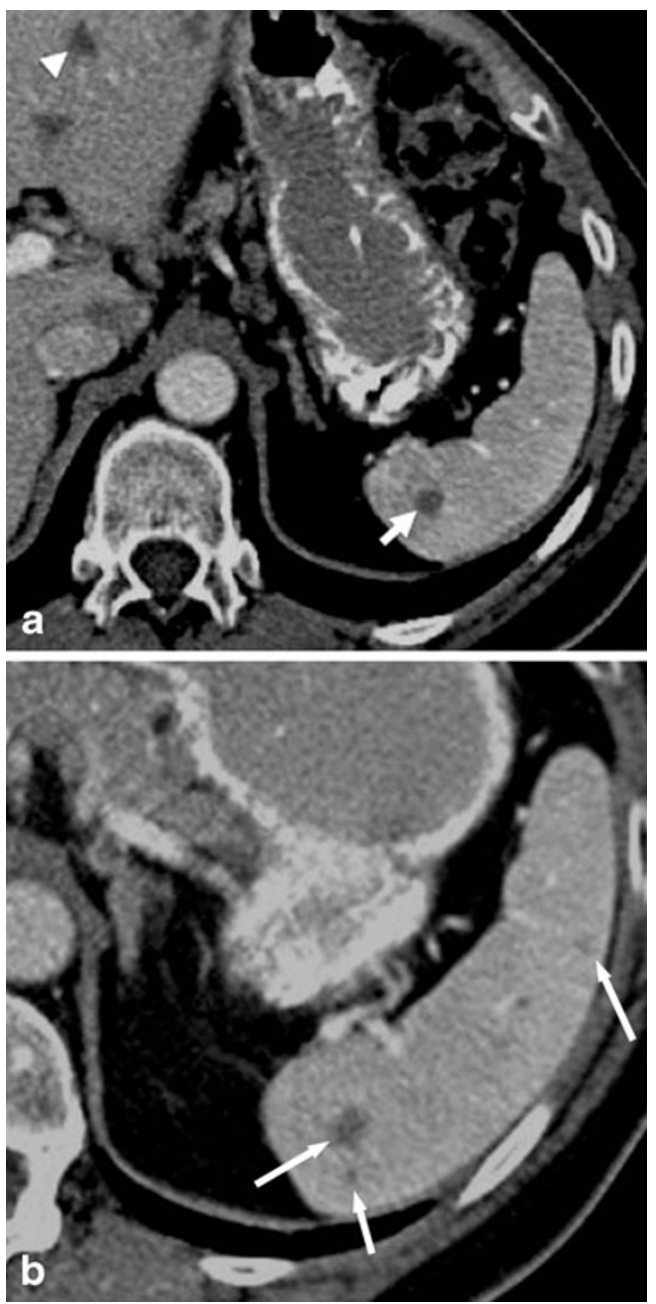

Fig. 10 a, b Transverse contrast-enhanced CT images acquired during the portal-venous phase at different levels in a 55-year-old woman with sarcoidosis affecting the liver (arrowhead) and the spleen (short arrow, long arrows)

found incidentally on diagnostic imaging or during autopsy, as most patients remain asymptomatic [33]. However, spontaneous splenic rupture had been reported as a potential complication [34]. Histopathologically, dilated sinusoids as well as fluid- and blood-filled cavities can be found within the splenic parenchyma in patients with peliosis [35].

On contrast-enhanced CT, peliosis exhibits multiple, small, ill-defined, hypodense lesions (Fig. 11). However, due to haemorrhage, peliosis lesions can present hyperdense as well. Different patterns of enhancement have been reported including early peripheral enhancement with delayed centripetal enhancement, similar to haemangiomas [36].

\section{Littoral cell angioma}

Littoral cell angiomas represent rare vascular tumours that arise from the cells that line the red pulp. They are usually 

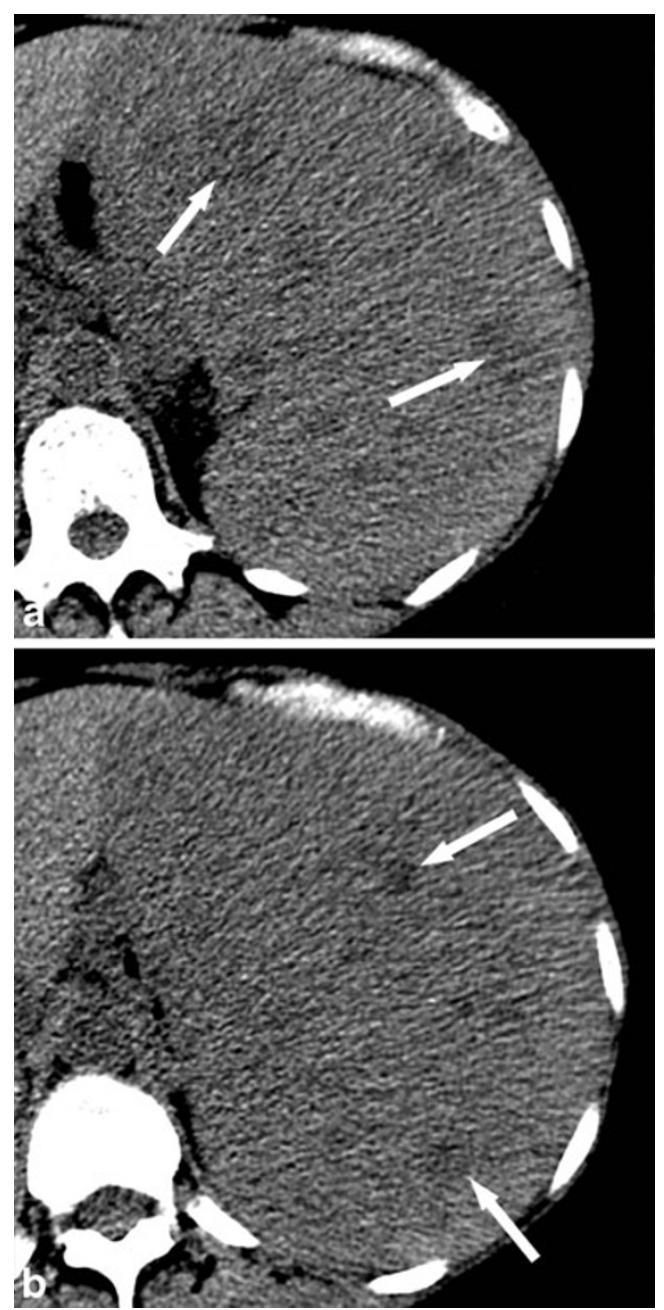

Fig. 11 a, b Transverse non-contrast-enhanced CT images acquired at two different levels in a 55-year-old woman with splenic peliosis, exhibiting multiple hypodense lesions of different size (arrows) within a massively enlarged spleen

detected incidentally, since most littoral cell angiomas remain asymptomatic. While the majority of littoral cell angiomas is benign, cases of malignant lesions have been reported [37]. More importantly, associations with colorectal carcinoma, renal cell carcinoma, hepatocellular carcinoma, lung cancer, lymphoma and pancreatic adenocarcinoma as well as meningioma have been reported [38].

On contrast-enhanced CT images, littoral cell angiomas usually present as multiple, ill-defined, hypodense lesions that show prolonged contrast-enhancement due to their histological structure of multiple vascular channels [39-41] (Fig. 12).

\section{Lymphoma}

Lymphoma represents the most common malignant tumour of the spleen $[42,43]$. Isolated primary splenic lymphoma
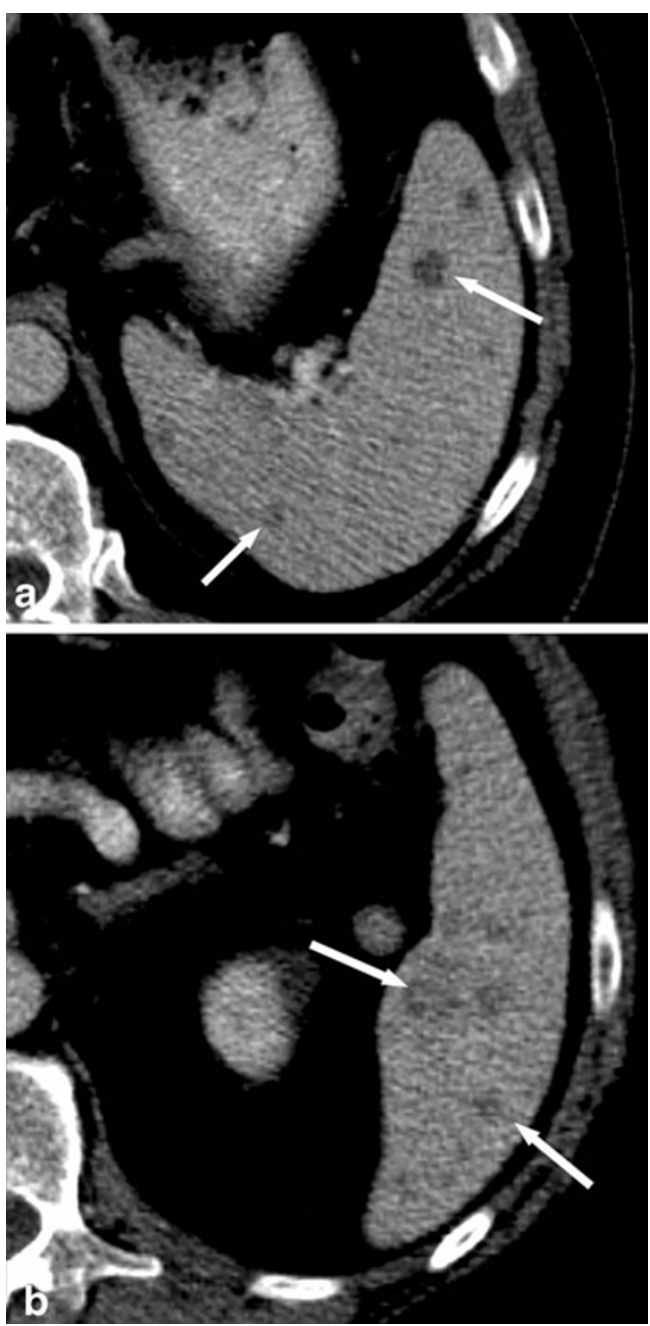

Fig. 12 a, b Transverse contrast-enhanced CT images acquired during the portal-venous phase at two different levels in a 55year-old man with littoral cell angioma, which presents as multiple hypodense, partially contrast-enhancing, lesions of different size (arrows)

represents less than $2 \%$ of all lymphomas [44]. In patients with lymphoma, the spleen is usually involved secondarily.

On contrast-enhanced CT images, it may be challenging to differentiate lymphoma nodules from sarcoidosis or fungal abscesses, which frequently occur in lymphoma patients due to immunodeficiency. However, in such cases, the presence of hilar lymphadenopathy is suggestive of splenic lymphoma [45], but should not be confused with sarcoidosis. Lymphoma of the spleen can present as splenomegaly without focal lesions, multiple small $(<1 \mathrm{~cm})$ or large $(<10 \mathrm{~cm})$ lesions, or a single solitary lesion (Fig. 13). The diagnosis of splenic lymphoma can be most easily made in the context of the clinical history and in knowledge of the disease. 


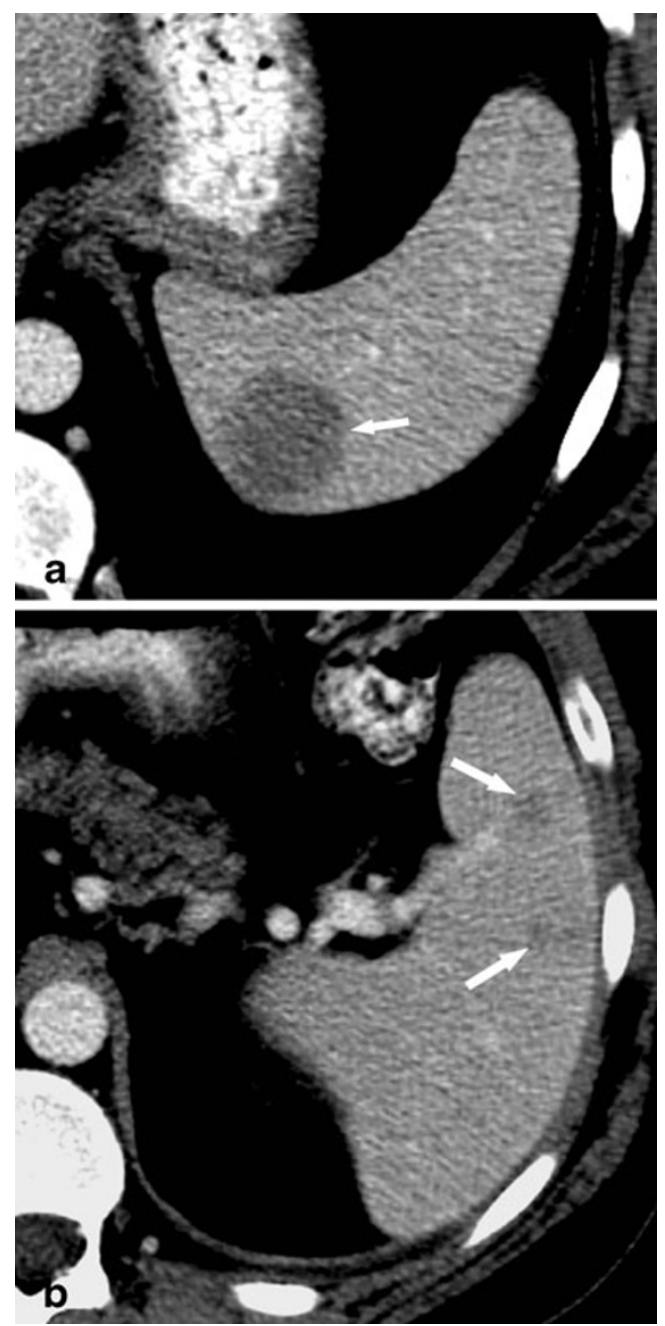

Fig. 13 a, b Transverse contrast-enhanced CT images acquired during the portal-venous phase at two different levels in a 55-year-old man with diffuse large B-cell lymphoma exhibiting multiple hypodense, mildly contrast-enhancing lesions within the spleen (arrows); with the latter usually being enlarged

\section{Metastases}

Metastases to the spleen usually occur in the context of multi-visceral, metastatic end-stage cancer [46]. Breast, lung, ovarian, colorectal and gastric carcinomas, as well as skin melanoma, are considered the most common primary sources [47], with skin melanoma accounting for the most aggressive type of splenic involvement, affecting up to $30 \%$ of patients [48, 49]. It is important to note that metastases from skin melanoma can present as hypodense on noncontrast-enhanced CT images.

On contrast-enhanced CT images, hypodense, ill-defined, contrast-enhancing lesions in patients with known malignancies need to be regarded as splenic metastases until proven otherwise. Metastases may, depending on the primary tumour, appear either hypodense or hyperdense (Fig. 14) during the portal-venous phase and can show cystic components.

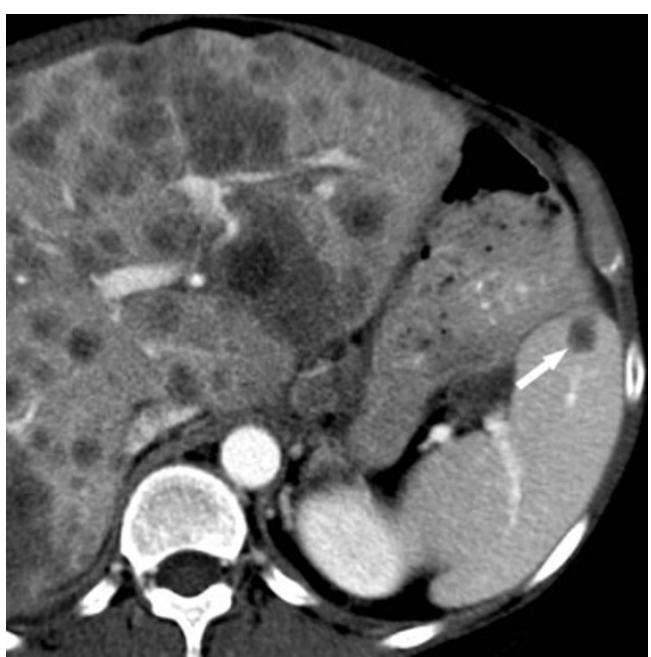

Fig. 14 Transverse contrast-enhanced $\mathrm{CT}$ image acquired during the portal-venous phase in a 47-year-old woman with metastatic ovarian cancer. The newly diagnosed hypodense lesion within the spleen (arrow) needs to be regarded as a metastasis unless proven otherwise

\section{Angiosarcoma}

Splenic angiosarcomas are rare but very aggressive tumours. Either solitary or multiple, contrast-enhancing lesions can be seen on CT [50-52]. The enhancement can be similar to that of haemangiomas. An early onset of metastasis, predominantly to the liver, is observed.

\section{Conclusions}

In general, the majority of hypodense splenic lesions on contrast-enhanced, portal-venous CT represent benign lesions that require no further work-up. However, certain imaging appearances — such as ill-defined lesion borders, presence of solid, contrast-enhancing components and increased attenuation of the lesion-must draw the attention of the radiologist to a potentially more relevant disease. For correct interpretation, hypodense lesions of the spleen need to be evaluated in the clinical context of the history, because CT imaging appearances of certain entities are overlapping and often cannot be distinguished with certainty (Table 1). In the presence of a newly diagnosed, hypodense lesion of the spleen on contrast-enhanced, portal-venous CT, the answers to the following questions can help in clarifying the diagnosis: Is there a known primary tumour? Does the patient have any other signs of metastatic disease? Does the patient suffer from sarcoidosis or tuberculosis? Does the patient have fever? Is there a recent history of trauma?

Open Access This article is distributed under the terms of the Creative Commons Attribution License which permits any use, distribution, and reproduction in any medium, provided the original author(s) and the source are credited. 
Table 1 Differential CT imaging features of hypodense lesions of the spleen

\begin{tabular}{|c|c|c|c|c|c|c|c|}
\hline & Distribution & $\begin{array}{l}\text { Number } \\
\text { of lesions }\end{array}$ & Margin & $\begin{array}{l}\text { Mass } \\
\text { effect }\end{array}$ & $\begin{array}{l}\text { Contrast } \\
\text { enhancement }\end{array}$ & Spleen size & Patient history \\
\hline Parasitic cyst & Random & $\begin{array}{l}\text { Solitary } \\
\text { Multiple }\end{array}$ & Well-defined & None & None & Normal & Hydatid disease (lung, liver) \\
\hline Congenital cyst & Random & Solitary & Well-defined & Possible & Trabeculae & Normal & - \\
\hline Neoplastic cyst & Random & $\begin{array}{l}\text { Solitary } \\
\text { Multiple }\end{array}$ & Well-/ill-defined & None & Yes & Normal & Primary tumour \\
\hline False cyst & Subcapsular & Solitary & Well-defined & None & None & Normal & Past splenic trauma \\
\hline $\begin{array}{l}\text { Traumatic } \\
\text { injury }\end{array}$ & Random & $\begin{array}{l}\text { Solitary } \\
\text { Multiple }\end{array}$ & Ill-defined & Possible & None & Normal & Trauma \\
\hline $\begin{array}{r}\text { Pyogenic } \\
\text { abscess }\end{array}$ & Random & $\begin{array}{l}\text { Solitary } \\
\text { Multiple }\end{array}$ & Ill-defined & Possible & $\begin{array}{l}\text { Rim } \\
\text { enhancement }\end{array}$ & Normal & $\begin{array}{l}\text { Infectious condition } \\
\text { (localised/systemic) }\end{array}$ \\
\hline $\begin{array}{l}\text { Sickle cell } \\
\text { disease }\end{array}$ & Random & Multiple & Ill-defined & None & None & $\begin{array}{l}\text { Normal } \\
\text { (early stage) } \\
\text { Small } \\
\quad \text { (late stage) }\end{array}$ & Sickle cell disease \\
\hline Infarction & $\begin{array}{l}\text { Oriented } \\
\text { towards } \\
\text { capsule }\end{array}$ & $\begin{array}{l}\text { Solitary } \\
\text { Multiple }\end{array}$ & Well-/ill-defined & None & Prolonged & Normal & $\begin{array}{l}\text { Left upper quadrant pain } \\
\text { Thromboembolic disease }\end{array}$ \\
\hline Hamartoma & Random & Solitary & Well-defined & None & Prolonged & Normal & $\begin{array}{l}\text { Mostly incidental finding; } \\
\text { tuberous sclerosis, } \\
\text { Wiskott-Aldrich-like syndrome }\end{array}$ \\
\hline Haemangioma & Random & $\begin{array}{l}\text { Solitary } \\
\text { Multiple }\end{array}$ & Well-/ill-defined & None & Centripetal & Normal & $\begin{array}{l}\text { Mostly incidental finding; } \\
\text { Beckwith-Wiedemann, } \\
\text { Klippel-Trenauney-Weber, } \\
\text { Turner syndrome }\end{array}$ \\
\hline Lymphangioma & Subcapsular & $\begin{array}{l}\text { Solitary } \\
\text { Multiple }\end{array}$ & Well-defined & Possible & Trabeculae & Normal & $\begin{array}{l}\text { Incidental finding in child, } \\
\text { young adult }\end{array}$ \\
\hline Sarcoidosis & Random & Multiple & Ill-defined & Possible & Yes & Enlarged & Sarcoidosis \\
\hline Peliosis & Random & Multiple & Ill-defined & Yes & $\begin{array}{l}\text { Similar to } \\
\text { haemangioma }\end{array}$ & Enlarged & Peliosis hepatis \\
\hline $\begin{array}{l}\text { Littoral cell } \\
\text { angioma }\end{array}$ & Random & Multiple & Ill-defined & None & Prolonged & Normal & $\begin{array}{l}\text { Colorectal carcinoma, renal } \\
\text { cell carcinoma, hepatocellular } \\
\text { carcinoma, lung cancer, } \\
\text { lymphoma, pancreatic carcinoma }\end{array}$ \\
\hline Lymphoma & Random & $\begin{array}{l}\text { Solitary } \\
\text { Multiple }\end{array}$ & Ill-defined & Yes & Mild & Enlarged & $\begin{array}{l}\text { Associated lymphadenopathy; } \\
\text { mostly patients with clinically } \\
\text { known lymphoma }\end{array}$ \\
\hline Metastases & Random & $\begin{array}{l}\text { Solitary } \\
\text { Multiple }\end{array}$ & Ill-defined & Possible & Yes & $\begin{array}{l}\text { Normal } \\
\text { Enlarged }\end{array}$ & $\begin{array}{l}\text { Breast, lung, ovarian, colorectal } \\
\text { and gastric carcinomas; skin } \\
\text { melanoma }\end{array}$ \\
\hline Angiosarcoma & Random & $\begin{array}{l}\text { Solitary } \\
\text { Multiple }\end{array}$ & Ill-defined & Possible & Yes & Normal & $\begin{array}{l}\text { Mostly discovered due to early } \\
\text { onset of distant metastases }\end{array}$ \\
\hline
\end{tabular}

\section{References}

1. Ekeh AP, Walusimbi M, Brigham E, Woods RJ, McCarthy MC (2010) The prevalence of incidental findings on abdominal computed tomography scans of trauma patients. J Emerg Med 38 (4):484-489. doi:10.1016/j.jemermed.2008.11.019

2. Fenchel S, Boll DT, Fleiter TR, Brambs HJ, Merkle EM (2003) Multislice helical CT of the pancreas and spleen. Eur J Radiol 45 (Suppl 1):S59-S72

3. Lamb PM, Lund A, Kanagasabay RR, Martin A, Webb JA, Reznek RH (2002) Spleen size: how well do linear ultrasound measurements correlate with three-dimensional CT volume assessments? Br J Radiol 75(895):573-577
4. Robertson F, Leander P, Ekberg O (2001) Radiology of the spleen. Eur Radiol 11(1):80-95

5. von Sinner WN, Stridbeck H (1992) Hydatid disease of the spleen. Ultrasonography, CT and MR imaging. Acta Radiol 33(5):459461

6. Urrutia M, Mergo PJ, Ros LH, Torres GM, Ros PR (1996) Cystic masses of the spleen: radiologic-pathologic correlation. Radiographics 16(1):107-129

7. Pedrosa I, Saiz A, Arrazola J, Ferreiros J, Pedrosa CS (2000) Hydatid disease: radiologic and pathologic features and complications. Radiographics 20(3):795-817

8. Giovagnoni A, Giorgi C, Goteri G (2005) Tumours of the spleen. Cancer Imaging 5(1):73-77. doi:10.1102/1470-7330.2005. 0002 
9. Tsakayannis DE, Mitchell K, Kozakewich HP, Shamberger RC (1995) Splenic preservation in the management of splenic epidermoid cysts in children. J Pediatr Surg 30(10):1468-1470

10. Dachman AH, Ros PR, Murari PJ, Olmsted WW, Lichtenstein JE (1986) Nonparasitic splenic cysts: a report of 52 cases with radiologicpathologic correlation. AJR Am J Roentgenol 147(3):537-542

11. Dawes LG, Malangoni MA (1986) Cystic masses of the spleen. Am Surg 52(6):333-336

12. Boscak A, Shanmuganathan K (2012) Splenic trauma: what is new? Radiol Clin North Am 50(1):105-122. doi:10.1016/ j.rcl.2011.08.008

13. Moore EE, Cogbill TH, Malangoni MA et al (1995) Organ injury scaling. Surg Clin North Am 75(2):293-303

14. Marmery H, Shanmuganathan K, Alexander MT, Mirvis SE (2007) Optimization of selection for nonoperative management of blunt splenic injury: comparison of MDCT grading systems. AJR Am J Roentgenol 189(6):1421-1427. doi:10.2214/AJR.07.2152

15. Becker CD, Mentha G, Terrier F (1998) Blunt abdominal trauma in adults: role of $\mathrm{CT}$ in the diagnosis and management of visceral injuries. Part 1: liver and spleen. Eur Radiol 8(4):553-562

16. Al-Hajjar N, Graur F, Hassan AB, Molnar G (2002) Splenic abscesses. Rom J Gastroenterol 11(1):57-59

17. Chun CH, Raff MJ, Contreras L et al (1980) Splenic abscess. Medicine (Baltimore) 59(1):50-65

18. Nelken N, Ignatius J, Skinner M, Christensen N (1987) Changing clinical spectrum of splenic abscess. A multicenter study and review of the literature. Am J Surg 154(1):27-34

19. Alonso Cohen MA, Galera MJ, Ruiz M et al (1990) Splenic abscess. World J Surg 14(4):513-516, discussion 516-517

20. de Bree E, Tsiftsis D, Christodoulakis M, Harocopos G, Schoretsanitis G, Melissas J (1998) Splenic abscess: a diagnostic and therapeutic challenge. Acta Chir Belg 98(5):199-202

21. Helton WS, Carrico CJ, Zaveruha PA, Schaller R (1986) Diagnosis and treatment of splenic fungal abscesses in the immunesuppressed patient. Arch Surg 121(5):580-586

22. Sharma SK, Smith-Rohrberg D, Tahir M, Mohan A, Seith A (2007) Radiological manifestations of splenic tuberculosis: a 23patient case series from India. Indian J Med Res 125(5):669-678

23. Thoeni RF, Margulis AR (1979) Gastrointestinal tuberculosis. Semin Roentgenol 14(4):283-294

24. Vanhoenacker FM, De Backer AI, Op de Beeck B et al (2004) Imaging of gastrointestinal and abdominal tuberculosis. Eur Radiol 14(Suppl 3):E103-E115. doi:10.1007/s00330-003-2047-9

25. Ohtomo K, Fukuda H, Mori K, Minami M, Itai Y, Inoue Y (1992) CT and MR appearances of splenic hamartoma. J Comput Assist Tomogr 16(3):425-428

26. Thompson SE, Walsh EA, Cramer BC et al (1996) Radiological features of a symptomatic splenic hamartoma. Pediatr Radiol 26 (9):657-660

27. Ramani M, Reinhold C, Semelka RC et al (1997) Splenic hemangiomas and hamartomas: MR imaging characteristics of 28 lesions. Radiology 202(1):166-172

28. Rabushka LS, Kawashima A, Fishman EK (1994) Imaging of the spleen: CT with supplemental MR examination. Radiographics 14 (2):307-332

29. Ros PR, Moser RP Jr, Dachman AH, Murari PJ, Olmsted WW (1987) Hemangioma of the spleen: radiologic-pathologic correlation in ten cases. Radiology 162(1 Pt 1):73-77

30. Disler DG, Chew FS (1991) Splenic hemangioma. AJR Am J Roentgenol 157(1):44

31. Vilanova JC, Capdevila A, Aldoma J, Delgado E (1994) Splenic epithelioid hemangioma: MR findings. AJR Am J Roentgenol 163 (3):747-748
32. Bezzi M, Spinelli A, Pierleoni M, Andreoli G (2001) Cystic lymphangioma of the spleen: US-CT-MRI correlation. Eur Radiol 11(7): 1187-1190

33. Tada T, Wakabayashi T, Kishimoto H (1983) Peliosis of the spleen. Am J Clin Pathol 79(6):708-713

34. Lashbrook DJ, James RW, Phillips AJ, Holbrook AG, Agombar AC (2006) Splenic peliosis with spontaneous splenic rupture: report of two cases. BMC Surg 6:9. doi:10.1186/1471- 2482-6-9

35. Tsokos M, Erbersdobler A (2005) Pathology of peliosis. Forensic Sci Int 149(1):25-33. doi:10.1016/j.forsciint.2004.05.010

36. Iannaccone R, Federle MP, Brancatelli G et al (2006) Peliosis hepatis: spectrum of imaging findings. AJR Am J Roentgenol 187(1):W43-W52. doi:10.2214/AJR.05.0167

37. Priego P, Rodriguez Velasco G, Griffith PS, Fresneda V (2008) Littoral cell angioma of the spleen. Clin Transl Oncol 10(1):61-63

38. Bhavsar T, Wang C, Huang Y, Karachristos A, Inniss S (2011) Littoral cell angiomas of the spleen associated with solid pseudopapillary tumor of the pancreas. World J Gastrointest Pathophysiol 2(3):53-56. doi:10.4291/wjgp.v2.i3.53

39. Levy AD, Abbott RM, Abbondanzo SL (2004) Littoral cell angioma of the spleen: CT features with clinicopathologic comparison. Radiology 230(2):485-490. doi:10.1148/radiol.2302030196

40. Shah S, Wasnik A, Pandya A, Bude RO (2011) Multimodality imaging findings in image- guided biopsy proven splenic littoral cell angioma: series of three cases. Abdom Imaging 36(6):735738. doi:10.1007/s00261-011-9697-x

41. Schneider G, Uder M, Altmeyer K, Bonkhoff H, Gruber M, Kramann B (2000) Littoral cell angioma of the spleen: CT and MR imaging appearance. Eur Radiol 10(9):1395-1400

42. Dachman AH, Buck JL, Krishnan J, Aguilera NS, Buetow PC (1998) Primary non- Hodgkin's splenic lymphoma. Clin Radiol 53(2):137-142

43. Metser U, Goor O, Lerman H, Naparstek E, Even-Sapir E (2004) PET-CT of extranodal lymphoma. AJR Am J Roentgenol 182 (6):1579-1586

44. Ahmed S, Horton KM, Fishman EK (2011) Splenic incidentalomas. Radiol Clin North Am 49(2):323-347. doi:10.1016/ j.rcl.2010.11.001

45. Leite NP, Kased N, Hanna RF et al (2007) Cross-sectional imaging of extranodal involvement in abdominopelvic lymphoproliferative malignancies. Radiographics 27(6):1613-1634. doi:10.1148/ rg. 276065170

46. Comperat E, Bardier-Dupas A, Camparo P, Capron F, Charlotte F (2007) Splenic metastases: clinicopathologic presentation, differential diagnosis, and pathogenesis. Arch Pathol Lab Med 131 (6):965-969

47. Griffin N, Burke C, Grant LA (2011) Common primary tumours of the abdomen and pelvis and their patterns of tumour spread as seen on multi-detector computed tomography. Insights Imaging 2 (3):205-214. doi:10.1007/s13244-011-0089-0

48. Berge T (1974) Splenic metastases. Frequencies and patterns. Acta Pathol Microbiol Scand A 82(4):499-506

49. Lam KY, Tang V (2000) Metastatic tumors to the spleen: a 25-year clinicopathologic study. Arch Pathol Lab Med 124(4):526-530

50. Ha HK, Kim HH, Kim BK, Han JK, Choi BI (1994) Primary angiosarcoma of the spleen. CT and MR imaging. Acta Radiol 35(5):455-458

51. Imaoka I, Sugimura K, Furukawa M, Kuroda S, Yasui K (1999) $\mathrm{CT}$ and MR findings of splenic angiosarcoma. Radiat Med 17 (1):67-70

52. Vanhoenacker FM, Op de Beeck B, De Schepper AM, Salgado R, Snoeckx A, Parizel PM (2007) Vascular disease of the spleen. Semin Ultrasound CT MR 28(1):35-51 